\title{
Inhibition of proliferation induced by anti-sense RNA of HDAC1 in MCF-7 cells
}

\author{
YIBAO ZHU ${ }^{1 *}$, QINJUN WEI $^{1 *}$, YAJIE LU $^{1}$, JUN YAO $^{1}$ and XIN CAO ${ }^{1,2}$ \\ ${ }^{1}$ Department of Biotechnology, Nanjing Medical University, Nanjing 210029; \\ ${ }^{2}$ Key Laboratory of Antibody Technology of the Ministry of Health, Nanjing 210029, P.R. China
}

Received October 31, 2008; Accepted April 27, 2009

DOI: 10.3892/mmr_00000166

\begin{abstract}
Acetylation and deacetylation are the main posttranslational modifications of histones. Increased deacetylation is associated with carcinogenesis, but the individual histone deacetylase (HDAC) responsible for this increase remains elusive. This study was designed to investigate the role of histone deacetylase 1 during tumorigenesis in MCF-7 human breast cancer cells. Anti-sense RNA was used to downregulate HDAC1 expression. RT-PCR analysis confirmed the efficiency of the anti-sense RNA, revealing that anti-sense RNA effectively downregulated HDAC1. The MTT assay showed that the proliferation of MCF-7 cells was inhibited and that cell activity was decreased. Cell cycle analysis identified cell cycle phase variations, with cells mainly arrested in the G1 and G2 phase. The anti-sense RNA of HDAC1 induced the inhibition of proliferation and cell cycle arrest in MCF-7 cells, suggesting it might have therapeutic applications as an antitumor agent in breast cancer.
\end{abstract}

\section{Introduction}

Histone acetyltransferases (HATs) and histone deacetylases (HDACs) are two opposing classes of enzymes which tightly control the equilibrium of histone acetylation (1). In the 1960s, Allfrey et al were the first to show that histones can control gene activation in higher organisms and that their post-translational modifications can affect RNA synthesis (2). Acetylation confers a negative charge on the positively charged histones, leading to the breakage of electrostatic attraction between histones and DNA. This in turn causes a localized relaxation of the chromatin, allowing gene transcription (3).

Correspondence to: Dr Xin Cao, Department of Biotechnology, Nanjing Medical University, Nanjing 210029, P.R. China

E-mail: caoxin@njmu.edu.cn

${ }^{*}$ Contributed equally

Abbreviations: HDAC1, histone deacetylase 1; HATs, histone acetyltransferases

Key words: anti-sense RNA, histone deacetylase 1, MCF-7 cells
An increasing body of evidence suggests that the disruption of HAT and HDAC activity is associated with carcinogenesis. An imbalance in acetylation and deacetylation has been found in several types of tumors (4). Missense mutations and truncations of p300 HAT occur in colorectal and gastric primary tumors. Loss of heterozygosity of p300 was reported in glioblastomas, hepatocellular carcinomas and leukemias $(5,6)$. Although to date direct alterations in the expression levels of HDACs have not been found to be associated with the pathogenesis of tumors, increased HDAC activity is associated with the repression of tumor suppressor genes and oncogenic translocation products (7). During tumorigenesis, tumor suppressor genes such as p16, p21 and gelsolin are deregulated $(8,9)$ due to HDAC activity on their promoters. In acute promyelocytic leukemia, the fusion protein PLZF-RAR $\alpha$ represses transcription through recruitment of a co-repressor protein complex that contains an HDAC. This results in unresponsiveness to the physiological concentration of retinoic acid (RA). When treated with an HDAC inhibitor, PLZF leukemia cells exhibit restored sensitivity to physiological concentrations of RA. This suggests that HDACs play an important role in the development of PLZF leukemia (10).

When an imbalance in the equilibrium between acetylation and deacetylation is observed during tumorigenesis, an alteration in HDAC activity is more evident than one in HAT activity. When tumor cells are treated with HDAC inhibitors, their proliferation is inhibited and they undergo cell cycle arrest and apoptosis $(11,12)$. These drugs have little or no effect on normal cells $(13,14)$. Thus, HDAC variation may play a role in carcinogenesis. Here, we used anti-sense RNA targeting HDAC1 to determine whether anti-sense RNA could be used for the specific inhibition of HDAC1 expression and whether this inhibition would result in antitumor effects. We demonstrated that specific downregulation of HDAC1 by anti-sense RNA inhibited the growth of MCF-7 cells in vitro, suggesting that HDAC1 might serve as a therapeutic target for human breast cancer.

\section{Materials and methods}

Cell culture. MCF-7 human breast cancer cells were acquired from the American Type Culture Collection (ATCC, Manassas, VA). Cells were grown in Dulbecco's modified Eagle's medium (DMEM) (Gibco, USA) supplemented with $10 \%$ fetal calf 
serm (FCS) (Gibco), 2 mM L-glutamine, $100 \mathrm{U} / \mathrm{ml}$ penicillin and $100 \mu \mathrm{g} / \mathrm{ml}$ streptomycin. Cells were maintained at $37^{\circ} \mathrm{C}$ in $5 \% \mathrm{CO}_{2}$, nourished every 3 days with complete medium and subcultured when confluency was reached.

Amplification of HDAC1. The specific primer pair for HDAC1 (GenBank accession no. NM_004964) was designed using Primer Designer 3.2 software. Homology with other human sequences and the formation of template secondary structures were carefully avoided. The HDAC1 primers consisted of the following sequences: (forward) 5'-GAAGGAATTCGACAA GGCCACCCAATGA-3' and (reverse) 5'-GAACAAGCTTCC TAACCGATCCCCAGAT-3'. Two restriction sites, EcoRI and HindIII, were added to the primers. The fragment of $H D A C l$ was then amplified using previously prepared human cDNA, with an expected amplification size of $731 \mathrm{bp}$. The cycling program was performed as follows: $94^{\circ} \mathrm{C}$ for $5 \mathrm{~min} ; 94^{\circ} \mathrm{C}$ for $30 \mathrm{sec}, 55^{\circ} \mathrm{C}$ for $30 \mathrm{sec}$, and $72^{\circ} \mathrm{C}$ for $1 \mathrm{~min}$ for 30 cycles; $72^{\circ} \mathrm{C}$ for $10 \mathrm{~min}$. The primer pair for the $\beta$-actin housekeeping gene comprised the following sequences: (forward) 5'-AAAGAC CTGTACGCCAACAC-3' and (reverse) 5'-GTCATACTCCTG CTTGCTGAT-3', with an amplification size of $219 \mathrm{bp}$.

Plasmid construction and identification. The fragment of HDAC1 was amplified and purified, and ligated into the pcDNA3.1(-) vector. Bacterial colonies were pooled and used for plasmid preparation. The positive clones were identified by PCR and further confirmed by sequencing.

Cell transfection. Cells were maintained in DMEM medium with $10 \%$ BSA. One day before transfection, cells were seeded into 24-well plates at a density of $3.0 \times 10^{4}$ cells per well. Transient transfections of MCF-7 cells were performed with the Lipofectamine 2000 System (Invitrogen) according to the manufacturer's instructions when cell confluence reached $70-80 \%$. The cells were harvested at different time points, and the experiments were performed.

Semi-quantitative analysis of HDAC1. Total RNA was extracted with TRIzol reagent (Takara), and cDNA was produced using a ReverTra Ace- $\alpha$-cDNA Kit (Toyobo). According to the manufacturer's instructions, $1 \mu \mathrm{g}$ of RNA was used to synthesize cDNA. The primers and conditions were identical to those used in the HDACl amplification. The RT-PCR products obtained were electrophoresed on a $2 \%$ agarose gel with ethidium bromide. Densitometric analysis was performed using Scion Image software, and the inhibitory rates of HDAC1 mRNA expression were calculated.

MTT assay. On the day before transfection, cells were seeded at a density of $2.5 \times 10^{3}$ cells/well in 96 -well plates in $100 \mu \mathrm{l}$ of DMEM supplemented with $10 \%$ FCS. Cultures were grown for 5 days. Each day, 5 wells were selected from each group of cells, and $20 \mu \mathrm{l}$ of PBS containing $5 \mathrm{mg} / \mathrm{ml}$ MTT (Sigma, USA) was added to each of these wells. The cells were incubated with MTT at $37^{\circ} \mathrm{C}$ for $4 \mathrm{~h}$, and the reaction was terminated with the addition of DMSO (150 $\mu \mathrm{l} /$ well). Cells were then incubated for an additional $15 \mathrm{~min}$. Absorbance was measured spectrophotometrically on a plate reader (Bio-Rad, USA) at $570 \mathrm{~nm}$.
A.

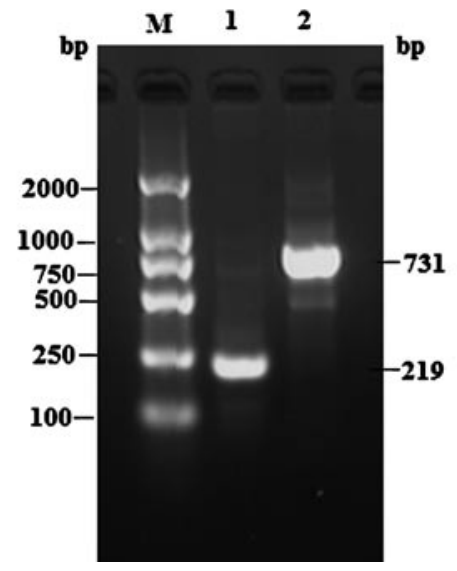

B.

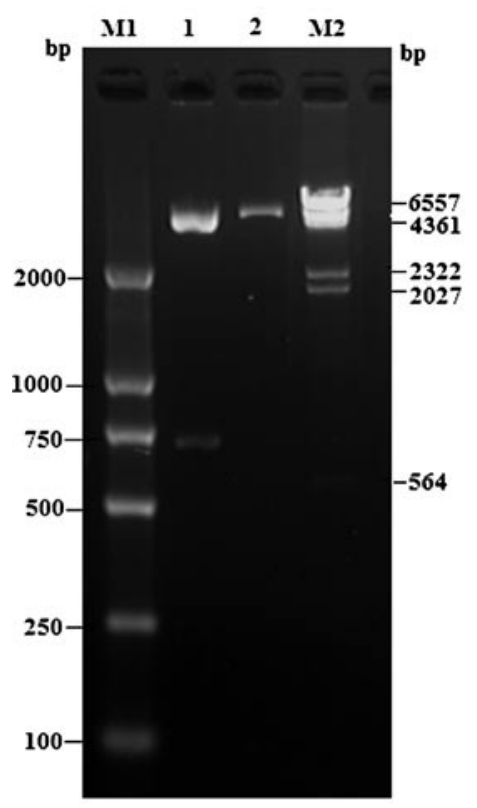

Figure 1. Construction and verification of the pcDNA3.1(-)-HDAC1 vector (A) Part of the amplified sequence of HDAC1 was constructed by PCR, with a product of $731 \mathrm{bp}$. (B) Recombined expression plasmids were digested with EcoRI and HindIII. The 731-bp HDAC1 fragment, cut from the pcDNA3.1HDAC1, is shown.

Cell cycle analysis. Cells were collected after a 72-h transfection. Equal amounts of the blank group (with DMEM substituted for transfection complex), the negative group (pcDNA3.1(-)control), the positive controls (TSA, $0.5 \mu \mathrm{mol} / \mathrm{l}$ ) and the anti-HDAC1 group were collected. Cells were washed twice with PBS, and then fixed in $75 \%$ ethanol and stored at $-20^{\circ} \mathrm{C}$ for $>30 \mathrm{~min}$. For analysis, the samples were washed once in PBS and stained with $400 \mu \mathrm{l}$ of a $50 \mu \mathrm{g} / \mathrm{ml}$ propidium iodide solution containing $20 \mu \mathrm{g} / \mathrm{ml} \mathrm{RNase}$ for $30 \mathrm{~min}$. Analysis was performed by flow cytometry using Cell Quest software.

Statistical methodology. Data were analyzed using one-way ANOVA and the Student Newman-Keuls test for multiple comparisons within treatment groups. $\mathrm{P}<0.05$ was considered to indicate a significant difference. 
A.

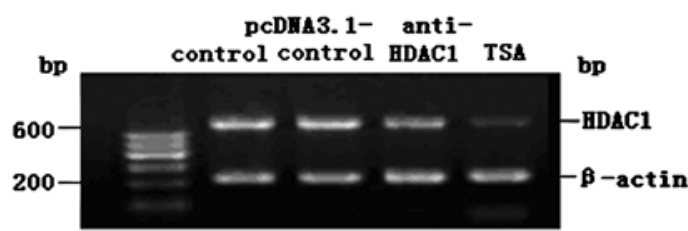

B.

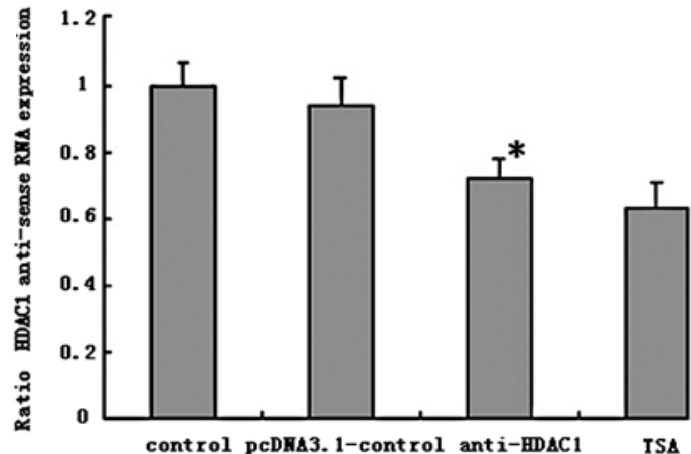

Figure 2. Anti-HDAC1 expression. (A) Semi-quantitative analysis of HDAC1 treated with anti-sense RNA. The anti-sense RNA inhibited HDAC1 expression to $43 \%$ in contrast to $\beta$-actin. No significant difference was observed with the control and pcDNA3.1-control. HDAC1 expression was more manifest in cells treated with TSA $(0.5 \mu \mathrm{mol} / \mathrm{l})$ for $48 \mathrm{~h}$ than in the anti-HDAC1 group (B) MTT assay analysis showing the proliferation activity of MCF-7 cells treated with pcDNA-control, anti-sense RNA or TSA $(0.5 \mu \mathrm{mol} / 1)$ for $48 \mathrm{~h}$ ${ }^{*} \mathrm{P}<0.05$.

\section{Results}

Amplification of HDACl. Since HDAC1 has so few transcripts, we chose to target base pairs 137-867 to downregulate it effectively. This fragment of HDAC1 was amplified with an apparent band (Fig. 1A).
The amplified fragments of HDAC1 and vector pcDNA3.1(-) were digested with EcoRI and HindIII for plasmid construction. Plasmid identification with EcoRI and HindIII indicated that HDAC1 had been inverted in pcDNA3.1(-), with electrophpresis revealing two apparent bands, one the $H D A C l$ gene and the other vector pcDNA3.1(-)(Fig. 1B). Further identification by sequencing confirmed that it was the targeted sequence, though inverted, while a BLAST database search revealed a $\mathrm{C} \rightarrow \mathrm{T}$ mutation at nt787. As this mutation would not globally affect anti-sense function, this clone was selected for further manipulation.

Anti-sense RNA downregulated HDACl. The anti-sense RNA plasmid was constructed and transfected into MCF-7 cells so as to test its efficiency. In the blank, negative and positive controls, as well as in the experimental group, treatment for $72 \mathrm{~h}$ significantly downregulated HDAC1. Electrophoresis revealed the band of the experimental group to be weaker than that of the negative control. Semi-quantitative analysis revealed that the anti-sense RNA inhibited HDAC1 expression to $43 \%$ in contrast to $\beta$-actin, while no significant difference was observed with the blank and negative controls, indicating that the anti-sense RNA effectively downregulated HDAC1. We also found that TSA, an HDAC inhibitor, suppressed HDAC1 expression in the positive control. This decrease was more apparent in the positive control than in the experimental group. TSA is a transcriptional agent that regulates the expression of many genes, so it was not surprising that it regulated HDAC1 expression (Fig. 2A).

Proliferation analysis showed that, among the blank, negative and positive controls and the experimental group, anti-sense RNA applied for $72 \mathrm{~h}$ inhibited the proliferation of MCF-7 cells and decreased cellular activity compared to the negative controls. No difference was observed with the blank and negative controls. Thus, anti-sense RNA suppressed HDAC1 expression and inhibited MCF-7 cell proliferation in vitro (Fig. 2B).
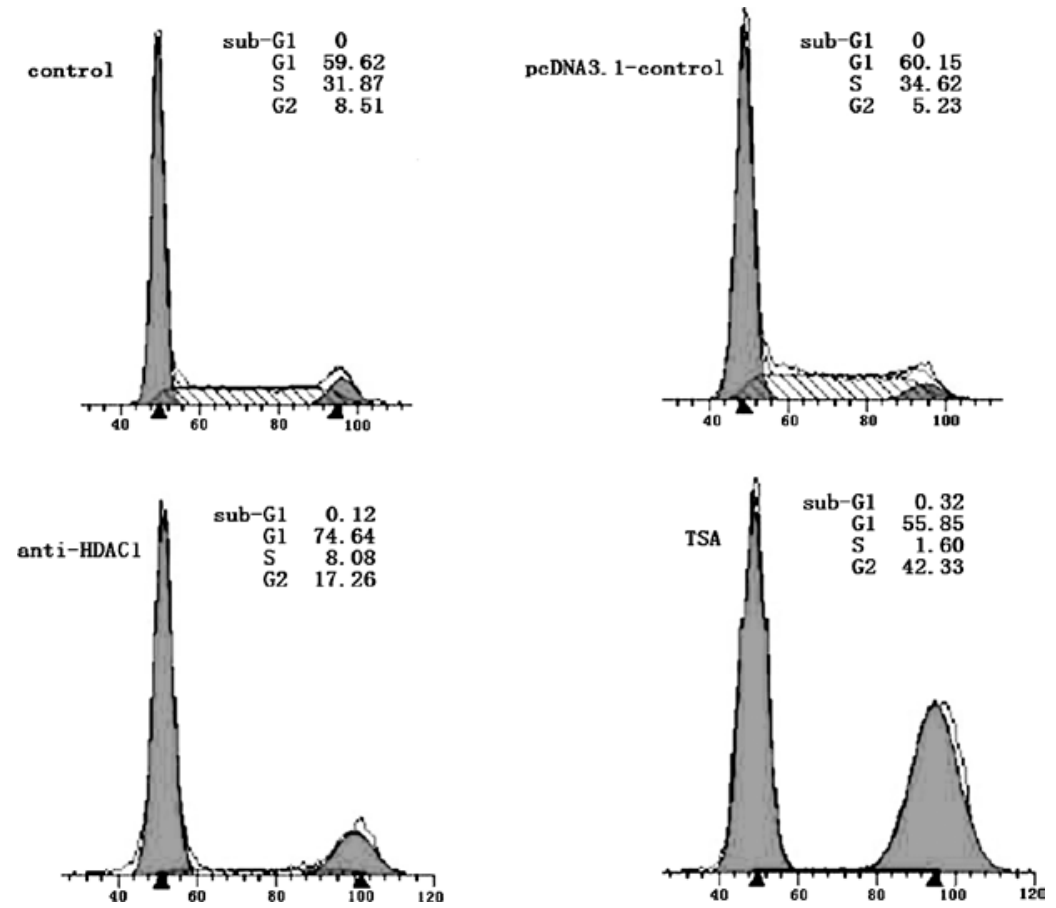

Figure 3. Effect of anti-HDAC1 on the MCF-7 cell cycle. Control, cells without transfection (medium only); pcDNA3.1-control, cells transfected with pcDNA3.1(-) plasmid (empty vector); anti-HDAC1, cells transfected with pcDNA3.1 + anti-HDAC1 plasmid; TSA, cells treated with TSA. 
Anti-sense RNA induced cell cycle arrest. Cell cycle analysis showed that, among the blank, negative and positive controls and the experimental group, anti-sense RNA applied for $72 \mathrm{~h}$ arrested the MCF-7 cell cycle. Cells were arrested in the G1 and G2 phase. There was no comparable variation in the blank control, indicating that anti-sense RNA induced cell cycle arrest in the MCF-7 cells (Fig. 3).

\section{Discussion}

HDAC1 was the first histone deacetylase to be identified, by Taunton et al in 1996. It is a 482-amino acid protein with a molecular weight of $55 \mathrm{kDa}$ (15). In 1997, several laboratories reported that HDAC1 induced transcriptional repression by binding to transcriptional repressors $(16,17)$. Increasing evidence suggests that the disruption of HDAC1 activity is associated with carcinogenesis, and that HDAC1 dysfunction is correlated with tumor formation. In acute promyelocytic leukemia, HDAC1 was recruited by a co-repressor protein complex, resulting in unresponsiveness to the physiological concentration of retinoic acid (RA). When treated with HDAC inhibitors, leukemia cells showed a restored sensitivity to the physiological concentration of RA (10). Choi et al reported that HDAC1 was overexpressed in gastric cancers compared to normal tissues in 17 of 25 samples. When treated with chemical therapies, the expression of HDAC1 in these cells was suppressed (18). Kim et al demonstrated that, in addition to inhibiting HDAC activity, the HDAC inhibitor TSA suppresses HDAC1 expression. TSA thus double suppresses HDAC1 at both the protein and mRNA level (19), suggesting that HDAC1 may play a vital role in deacetylation modification.

In this study, we first conducted stable transfection with G418. Our previous experiments had established that $400 \mathrm{mg} / \mathrm{l}$ of G418 was the lowest dose that could be applied while keeping cells alive for two weeks, so $400 \mathrm{mg} / \mathrm{l}$ of G418 was seleced for the screening dose. During stable transfection, $400 \mathrm{mg} / \mathrm{l}$ of G418 was added after a 48-h transfection. Days later, we found that extensive apoptosis had occurred in the anti-sense group; after 2 weeks, no living cells remained. In contrast, there were a few living cells in the negative group. The same results were obtained when the stable transfection was repeated. We reasoned that anti-sense RNA suppressed HDAC1 and downregulated its expression in much the same way as an HDAC inhibitor, causing the observed cytotoxicity. Thus, transient transfections of $72 \mathrm{~h}$ were selected for further experiments.

Consistent with Kim et al, we demonstrated that TSA suppressed HDAC1. In the present study, this suppression was more potent than that achieved by anti-sense RNA. Possibly, TSA acted as a transcriptional repressor, regulating the transcription of multiple genes, including HDACs, through a mechanism other than histone acetylation modification. Proliferation and cell cycle analysis revealed that cellular proliferation was inhibited and the cell cycle was arrested after transfection with anti-sense RNA. Analysis of the sequences of HDAC1-8 revealed that HDAC1 and 2 share a common sequence in the region of the anti-sense RNA, while HDAC1 shares no common sequences with the other HDACs. Thus, our anti-sense RNA downregulated HDAC1 and possibly also partially inhibited HDAC2. This downregulation of HDAC2 might also have contributed to the observed cell cycle effects. HDAC1 has a number of significant domains besides its acetyl-domain. It often interacts with the transcription repressors SIN3, N-CoR and Smads, and functions in a multiprotein complex $(20,21)$. In vitro expression of HDAC1 in E. coli showed that His-HDAC1 or GST-HDAC1 displayed no acetyltransferase activity. It was reported that components or co-factors in the complex were the key factors stimulating HDAC1 function. Suppression of HDAC1 via anti-sense RNA would affect the integrity of any complex containing HDAC1 $(22,23)$, Thus, in addition to the cellular effect imposed by the suppression of HDAC1, disruption of the integrity of the complex might explain the cell cycle effects observed.

By manipulating $\mathrm{HDACl}$ alone, it is possible to arrest the growth of MCF-7 cells. In the present study, no apparent compensation by HDAC2-8 was observed, possibly due to their having a dissimilar function. In addition, HDACs may have different substrates, some aimed at histones and others correlated with non-histones. Evidence suggests that the transcriptional regulation caused by HDAC inhibitors might not be solely attributable to the level of histone acetylation, as the acetylation of non-histone proteins, such as p53, GATA-1, HSP-90 or tubulin, has also been described $(24,25)$.

\section{Acknowledgements}

This work was supported in part by grants from the Jiangsu Natural Science Foundation (BK2008442) and the Scientific Foundation of Nanjing Medical University (08NMUZ007).

\section{References}

1. Gregory PD, Wagner K and Horz W: Histone acetylation and chromatin remodeling. Exp Cell Res 265: 195-202, 2001.

2. Allfrey VG, Littau VC and Mirsky AE: The role of histone in regulation ribonucleic acid synthesis in the cell nucleus. Proc Natl Acad Sci USA 49: 414-421, 1963.

3. Praveen KS and Kul BT: Histone deacetylase inhibitors as therapeutic target. Curr Res Inform Pharmaceut Sci 5: 9-18, 2004.

4. Cress WD and Seto E: Histone deacetylases, transcriptional control and cancer. Cell Physiol 184: 1-16, 2000.

5. Giles RH, Peters DJ and Breuning MH: Conjunction dysfunction: $\mathrm{CBP} / \mathrm{p} 300$ in human disease. Trends Genet 14: 178-183, 1998.

6. Gayther SA, Batley SJ, Linger L, Bannister A, Thorpe K, Chin SF, Daigo Y, Russell P, Wilson A, Sowter HM, Delhanty JD, Ponder BA, Kouzarides $\mathrm{T}$ and Caldas C: Mutations truncating the EP300 acetylase in human cancers. Nat Genet 24: 300-303, 2000.

7. Mei S, Ho AD and Mahlknecht U: Role of histone deacetylase inhibitors in the treatment of cancer. Int J Oncol 25: 1509-1519, 2004.

8. Hoshikawa Y, Kwon HJ, Yoshida M Horinouchi S and Beppu T: Trichostatin A induces morphological changes and gelsolin expression by inhibiting histone deacetylase in human carcinoma cell lines. Exp Cell Res 214: 189-197, 1994.

9. Saito A, Yamashita T, Mariko Y, Nosaka Y, Tsuchiya K, Ando T, Suzuki T, Tsuruo T and Nakanishi O: A synthetic inhibitor of histone deacetylase, MS-27-275, with marked in vivo anti-tumor activity against human tumors. Proc Natl Acad Sci USA 96: 4592-4597, 1999.

10. He LZ, Guidez F, Tribioli C, Peruzzi D, Ruthardt M, Zelent A and Pandolfi PP: Distinct interactions of PML-RAR alpha and PLZF-RAR alpha with co-repressors determine differential responses to RA in APL. Nat Genet 18: 126-135, 1998.

11. Marks P and Rifkind RA: Histone deacetylases and cancer: causes and therapies. Nat Rev Cancer 1: 194-202, 2001.

12. Johnstone RW and Licht JD: Histone deacetylase inhibitors in cancer therapy: is transcription the primary target? Cancer Cell 4: $13-18,2003$ 
13. Huang L and Arthur BP: Suberoylanilide hydroxamic acid as a potential therapeutic agent for human breast cancer treatment. Mol Med 6: 849-866, 2000.

14. Brinkmann H, Dahler AL, Popa C, Serewko MM, Parsons PG, Gabrielli BG, Burgess AJ and Saunders NA: Histone hyperacetylation induced by histone deacetylase inhibitors is not sufficient to cause growth inhibition in human dermal fibroblasts. J Biol Chem 276: 22491-22499, 2001.

15. Taunton J, Hassig CA and Schreiber SL: A mammalian histone deacetylase related to the yeast transcriptional regulator Rpd3p. Science 272: 408-411, 1996.

16. Nagy L, Kao HY, Chakravarti D, Lin RJ, Hassig CA, Ayer DE, Schreiber SL and Evans RM: Nuclear receptor repression mediated by a complex containing SMRT, mSin3A and histone deacetylase. Cell 89: 373-380, 1997.

17. Alland L, Muhle R, Hou H Jr, Potes J, Chin L, Schreiber-Agus N and DePinho RA: Role for N-CoR and histone deacetylase in Sin3 mediated transcriptional repression. Nature 387: 49-55, 1997.

18. Choi JH, Kwon HJ, Yoon BI, Kim JH, Han SU, Joo HJ and Kim DY: Expression profile of histone deacetylase 1 in gastric cancer tissues. Jpn J Cancer Res 92: 1300-1304, 2001.

19. Kim MS, Kwon HJ, Lee YM, Baek JH, Jang JE, Lee SW, Moon EJ, Kim HS, Lee SK, Chung HY, Kim CW and Kim KW: Histone deacetylases induce angiogenesis by negative regulation of tumor suppressor genes. Nat Med 7: 437-443, 2001.
20. Grozinger CM and Schreiber SL: Deacetylase enzymes: biological functions and the use of small molecule inhibitors. Chem Biol 9: 3-16, 2002.

21. Liu X, Sun Y, Weinberg RA and Lodish HF: Ski/Sno and TGF- $\beta$ signaling. Cytokine Growth Factor Rev 12: 1-8, 2001.

22. Fischle W, Dequiedt F, Hendzel MJ, Guenther MG, Lazar MA, Voelter W and Verdin E: Enzymatic activity associated with class-II HDACs is dependent on a multiprotein complex containing HDAC3 and SMRT/N-CoR. Mol Cell 9: 45-57, 2002.

23. Imai SI, Armstrong CM, Kaeberlein $M$ and Guarente L: Transcriptional silencing and longevity protein Sir2 is an NADdependent histone deacetylase. Nature 403: 795-800, 2000.

24. Bali P, Pranpat M, Bradner J, Balasis M, Fiskus W, Guo F, Rocha K, Kumaraswamy S, Boyapalle S, Atadja P, Seto E and Bhalla K: Inhibition of histone deacetylase 6 acetylates and disrupts the chaperone function of heat shock protein 90: a novel basis for anti-leukemia activity of histone deacetylase inhibitors. J Biol Chem 280: 26729-26734, 2005.

25. Di Gennaro E, Bruzzese F, Caraglia M, Abruzzese A and Budillon A: Acetylation of proteins as novel target for antitumor therapy: Review article. Amino Acids 26: 435-441, 2004. 